\title{
卫
}

\section{Functionality of ethylene filters}

Effects of filter type and location in reefer

Jan Verschoor

Leo Lukasse

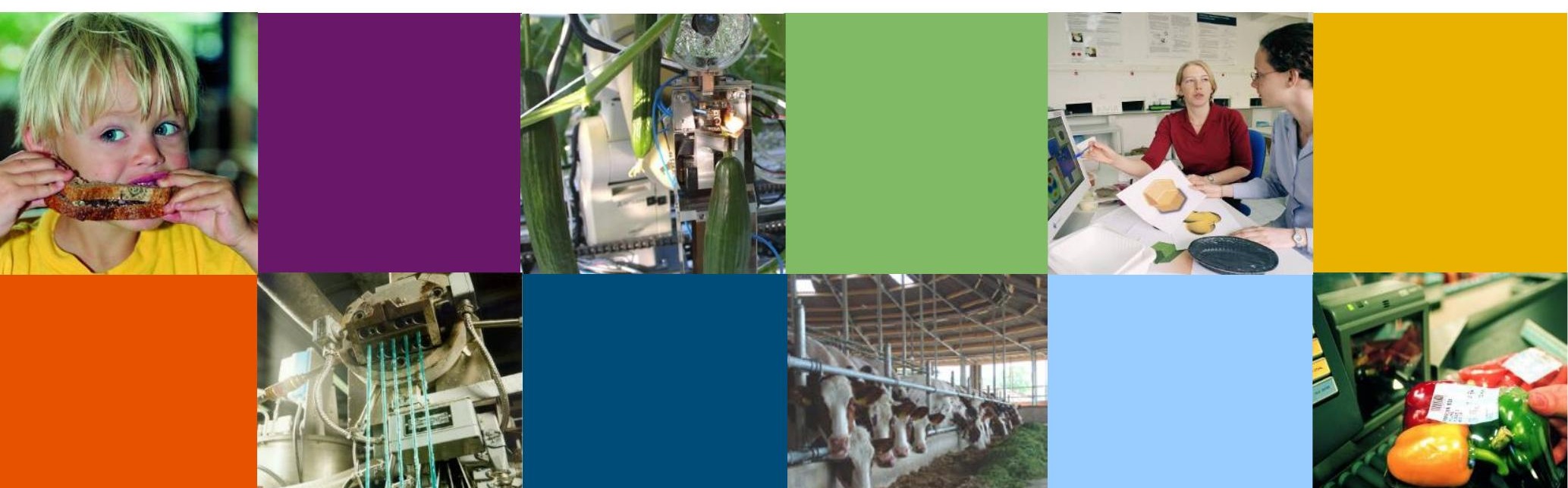




\section{Colophon}

$\begin{array}{ll}\text { Title } & \text { Functionality of ethylene filters } \\ \text { Author(s) } & \text { Jan Verschoor } \\ & \text { Leo Lukasse } \\ \text { Number } & 1675 \\ \text { Date of publication } & \text { 26 September 2016 } \\ \text { Version } & \text { End version } \\ \text { Confidentiality } & \text { Yes, September 2020 } \\ \text { OPD code } & \text { 16620268 } \\ \text { Approved by } & \text { Janneke de Kramer } \\ \text { Review } & \text { Intern } \\ \text { Name reviewer } & \text { Jan Verschoor, Leo Lukasse } \\ \text { Client } & \text { Maersk Line }\end{array}$

Wageningen Food \& Biobased Research

P.O. Box 17

NL-6700 AA Wageningen

Tel: +31(0)317480084

E-mail: info.fbr@wur.nl

Internet: www.wur.nl/foodandbiobased-research

(C) Wageningen Food \& Biobased Research, institute within the legal entity Stichting Wageningen Research All rights reserved. No part of this publication may be reproduced, stored in a retrieval system of any nature, or transmitted, in any form or by any means, electronic, mechanical, photocopying, recording or otherwise, without the prior permission of the publisher. The publisher does not accept any liability for inaccuracies in this report.

This report can be downloaded for free from September 2020 at https://doi.org/10.18174/563048 or at www.wur.nl/wfbr (under publications). 


\section{Abstract}

This project aims to assess the efficacy of disposable ethylene filters in reefer transport dependent on the mounting position (on return air grid or at door end) and brand (Bioconservacion, Ozeano). Also the effects of running the vacuum pump for $\mathrm{CO}_{2}$ scrubbing on ethylene removal was evaluated.

The ethylene removal rate in an MMAU reefer container Starcare 40ft. was monitored in a series of experiments with different test conditions related to banana transport. All tests were performed at Tset $=13.5^{\circ} \mathrm{C}, \mathrm{FAE}$ closed (except for last test), and liquid water on the floor to ensure high RH without risking condensation on filters. A CA curtain supplied by Maersk Line was installed during all tests.

Table below gives an overview of the effects of test conditions on ethylene reduction:

\begin{tabular}{|c|c|c|}
\hline & $\begin{array}{l}\text { ethylene } \\
\text { reduction } \\
\text { (ml/h) }\end{array}$ & $\begin{array}{l}\text { ethylene reduction } \\
(\mathrm{ml} / \mathrm{h}) \text { additional } \\
\text { to leak rate }\end{array}$ \\
\hline 1. vacuum pump OFF and without ethylene filters. (=leak rate) & 0.62 & \\
\hline 2. vacuum pump $\mathrm{ON}$ and without ethylene filters. & 0.83 & 0.21 \\
\hline $\begin{array}{l}\text { 3. vacuum pump OFF and two Bioconservacion ethylene filters in return } \\
\text { air grid. }\end{array}$ & 1.88 & 1.26 \\
\hline 4. vacuum pump OFF and two Ozceano ethylene filters in return air grid. & 1.46 & 0.84 \\
\hline $\begin{array}{l}\text { 5. vacuum pump OFF and two Bioconservacion ethylene filters at door- } \\
\text { end. }\end{array}$ & 1.13 & 0.51 \\
\hline $\begin{array}{l}\text { 6. vacuum pump OFF and without ethylene filters, FAE (Fresh Air } \\
\text { Exchange) set to } 15 \mathrm{CMH}\end{array}$ & 19.42 & 18.78 \\
\hline
\end{tabular}

Capacity to remove ethylene is 33\% lower for the Ozeano filters compared to Bioconservacion mounted at return air grid.

Air speed is a major factor in filter efficacy:

Ethylene reduction was 60\% lower when Bioconservacion filters were placed at the door end compared to at the return air grid. Air speed near the filters when placed on return air grid or near the door end showed average airspeeds of $3.9 \mathrm{~m} / \mathrm{s}$ near the return air grid and $0.3 \mathrm{~m} / \mathrm{s}$ near the door end.

Regular setting of Fresh Air Exchange (FAE) for bananas of $15 \mathrm{CMH}$ resulted in $18.78 \mathrm{ml}$ ethylene reduction per hour. 


\section{Content}

Abstract 3

1 Introduction $\quad 5$

1.1 Background 5

1.2 Intended results 5

2 Experimental setup $\quad 6$

2.1 Ethylene filters 6

2.2 Ethylene filter mounting $\quad 7$

2.3 Ethylene concentration monitoring $\quad 8$

2.4 Ethylene measurements 8

2.5 Air speed measurements 8

3 Results 9

4 Discussion $\quad 12$

5 Conclusions 13

References $\quad 14$ 


\section{Introduction}

Recently Maersk Line encountered issues with bleeding ethylene filters. This has raised the question how to position the filters in containers, and in which shipments the filters are needed. Henrik Lindhardt has asked Leo Lukasse to propose an project plan to address these topics. Due to time pressure this project only addressed the functionality aspect. The aspect of the need of ethylene filters may be addressed by a separate proposal in due time.

\subsection{Background}

Maersk Line installs and pays the one-time-use ethylene absorption filters for CA shipments of bananas and avocados. Concerns are the purchase costs, handling and disposal after the trip. Main concern is that in some trips the return-air-grid-mounted filters turn wet and a very-hardto-remove purple liquid starts to drip on the cargo. Suspicion is that the water source is somehow close to the return air grid and therefore different placement is considered advantageous. This project aims to assess the efficacy of the filters dependent on the mounting position and brand. Also the effect of running the vacuum pump for $\mathrm{CO}_{2}$ scrubbing on ethylene removal was to be tested.

\subsection{Intended results}

The intended result are:

- clarity on the efficacy of ethylene filter placement as a function of location

- comparison of two filter brands

- clarity on the effects of the vacuum pump for $\mathrm{CO}_{2}$ scrubbing on ethylene removal 


\section{Experimental setup}

The ethylene removal rate in an MMAU reefer container Starcare 40ft. HC (MMAU103.8582) was monitored in a series of experiments with different test conditions. All tests were performed at Tset $=13.5^{\circ} \mathrm{C}, \mathrm{FAE}$ closed (except for last test), and liquid water on the floor to ensure high $\mathrm{RH}$ without risking condensation on filters. A CA curtain supplied by Maersk Line was installed during all tests.

To assess the functionality of ethylene filters by type, as a function of position, ethylene decay curves were assessed. An ethylene decay curve is assessed by first injecting a pre-defined amount of ethylene, and then starting the test during which the gradual decay of ethylene is monitored. The following cases were tested:

1. vacuum pump OFF and without ethylene filters.

2. vacuum pump $\mathrm{ON}$ and without ethylene filters.

3. vacuum pump OFF and two Bioconservacion ethylene filters in return air grid.

4. vacuum pump OFF and two Ozceano ethylene filters in return air grid.

5. vacuum pump OFF and two Bioconservacion ethylene filters at door-end.

6. vacuum pump OFF and without ethylene filters, FAE (=Fresh Air Exchange) set to15 CMH $\left(=\mathrm{m}^{3} / \mathrm{h}\right)$

Last test was added to quantify effect of normal FAE setting for banana transport on ethylene removal capacity

Air flow velocity adjacent to the filters was measured in both situation 3 and 5 to better understand possible differences in ethylene absorption as a result of filter positioning in the reefer.

\subsection{Ethylene filters}

Filters were obtained from Maersk Line. For each test new filters were used.

Active ingredient is potassium permanganate $\left(\mathrm{KMnO}_{4}\right.$, Bioconservacion) or sodium permanganate $\left(\mathrm{NaMnO}_{4}\right.$, Ozeano). Permanganate is a strong oxidant that chemically converts ethylene to $\mathrm{CO}_{2}$. The two brands, Ozeano and Bioconservacion have slightly different design, see pictures. Approx. dimensions: $4 \mathrm{~cm}$ diameter and length $90 \mathrm{~cm}$ (Ozeano) or $99 \mathrm{~cm}$ (Bioconservacion).

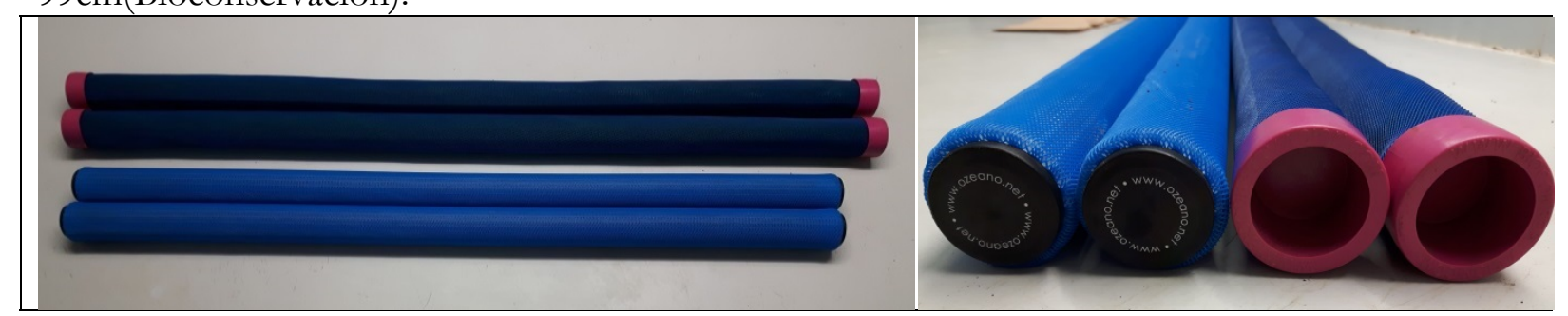

Etbylene filters from Bioconservacion (pink end caps) and Ozeano (black end caps) 


\subsection{Ethylene filter mounting}

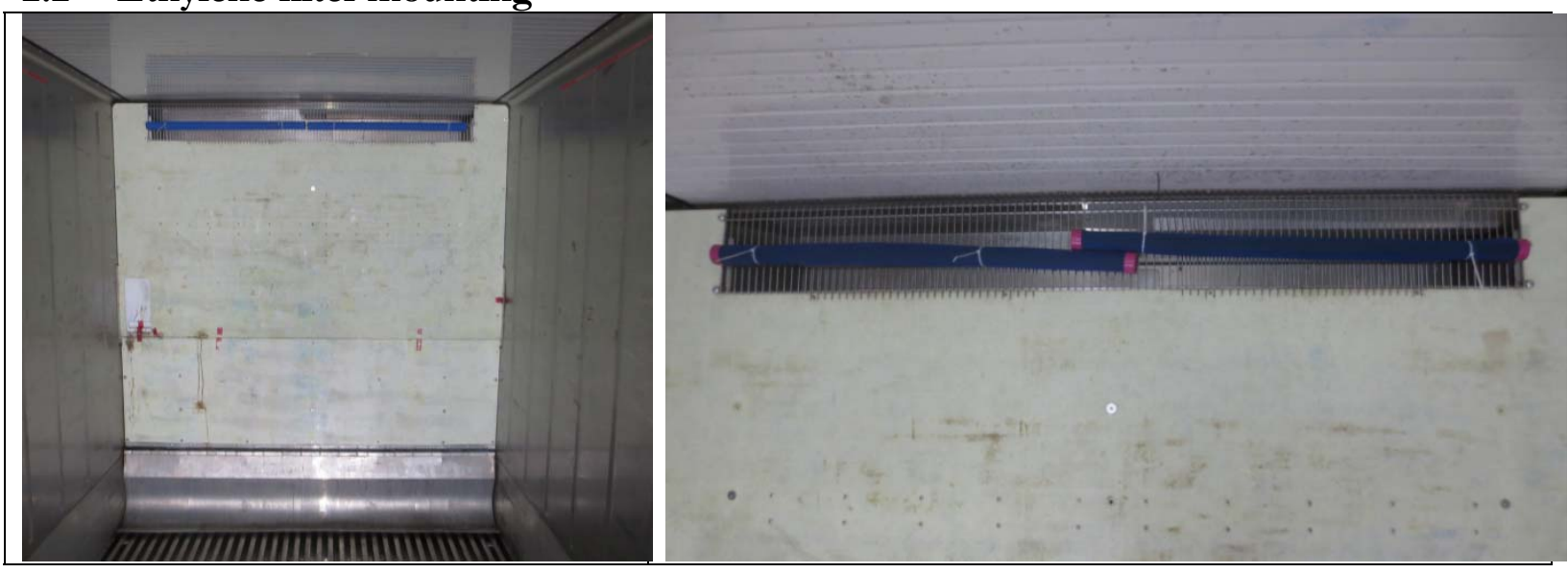

Installation of etbylene filters in front-end of cargo hold on return air grid using tie-wraps. (For tests 3

(Biococervacion, right picture) and 4(Ozeano, left picture).

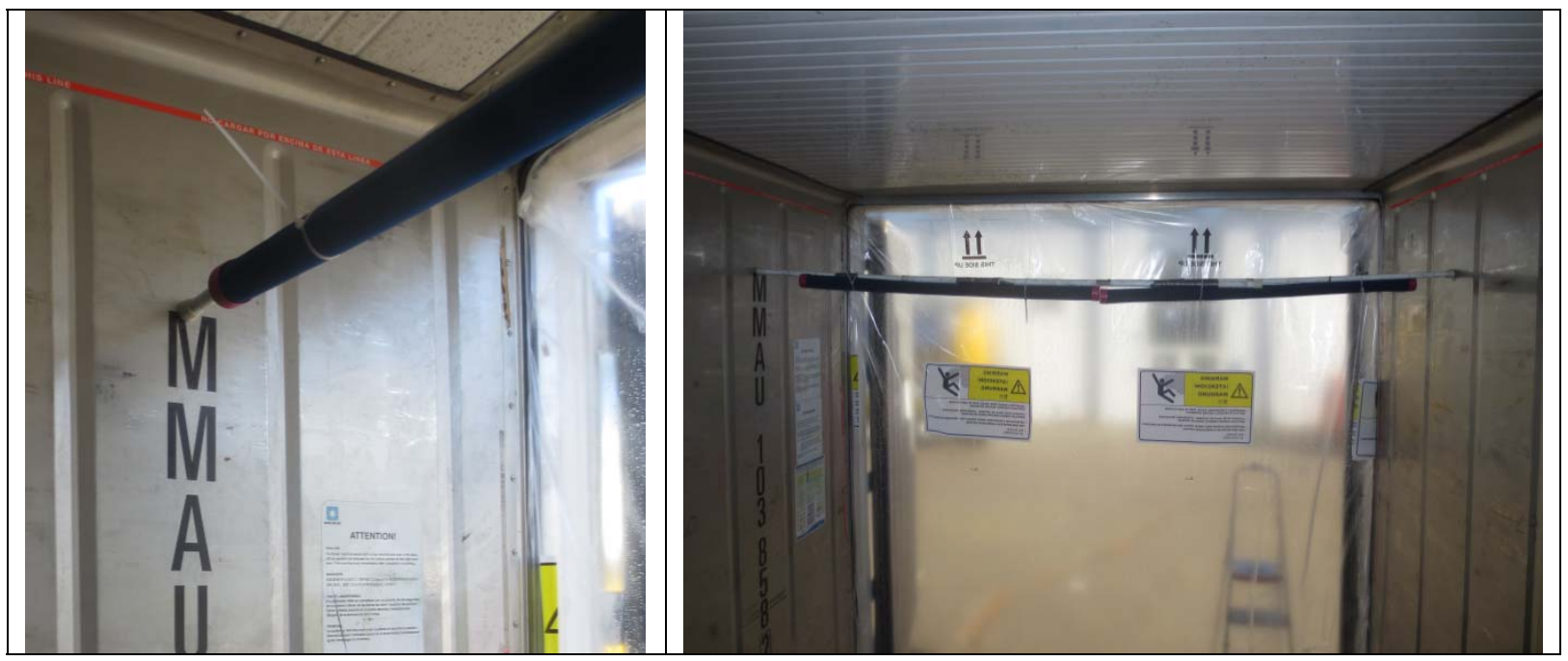

Installation of Bioconservacion ethylene filters in back-end of cargo bold using a spring-extendable bar and tiewraps for test 5 . 


\subsection{Ethylene concentration monitoring}

Pure ethylene (Linde Gas, Netherlands) was injected into the empty reefer using tubing under the door rubber and through the CA curtain (approx. 750-1000 ppb). End of the tubing was mounted on a blue crate (just visible in adjacent picture) some $50 \mathrm{~cm}$ from the floor and 2 meter from the door end to ensure immediate mixing of added ethylene in the air circulation. After injection of ethylene the tube used was flushed with clean air to prevent slow release of pure ethylene from this tubing during tests. After flushing this tube was closed. A separate tube for ethylene measurements was installed in a similar manner on the other side of the crate in the cargo hold. This to prevent the possibility of interference of the injected pure ethylene on ethylene measurements.

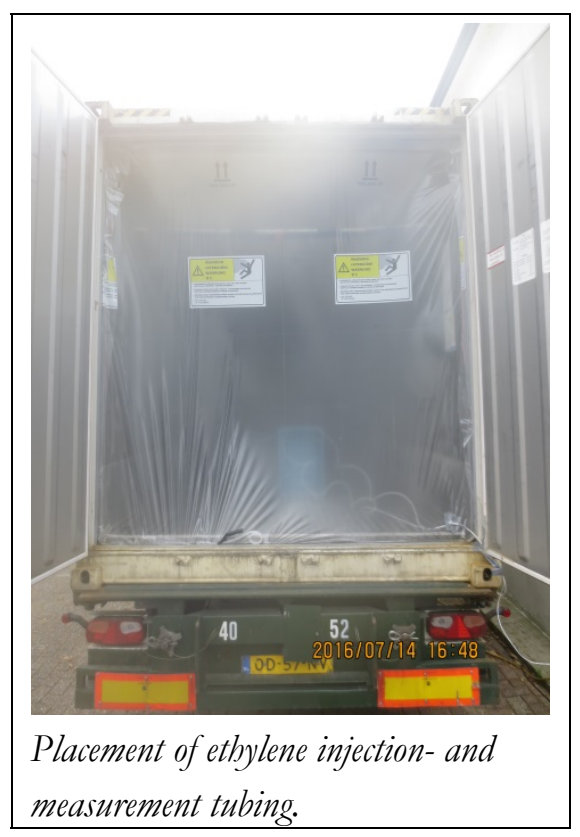

\subsection{Ethylene measurements}

Ethylene was monitored using a photoacoustic laser detector (ETD300, SensorSense, Netherlands). The detector was calibrated prior to use using certified calibration gas in the $1000 \mathrm{ppb}$ range with nitrogen as balance gas (Linde Gas, Netherlands).

The ETD300 is a very accurate and ethylene specific detector measuring every 5-10 seconds, enabling to monitor ethylene concentrations in time very accurately (resolution 0.3 ppb) (Vries 1996, Cristescu, Persijn et al. 2008). The detector was placed just outside the reefer. Air from the reefer cargo hold was drawn continuously with a sample

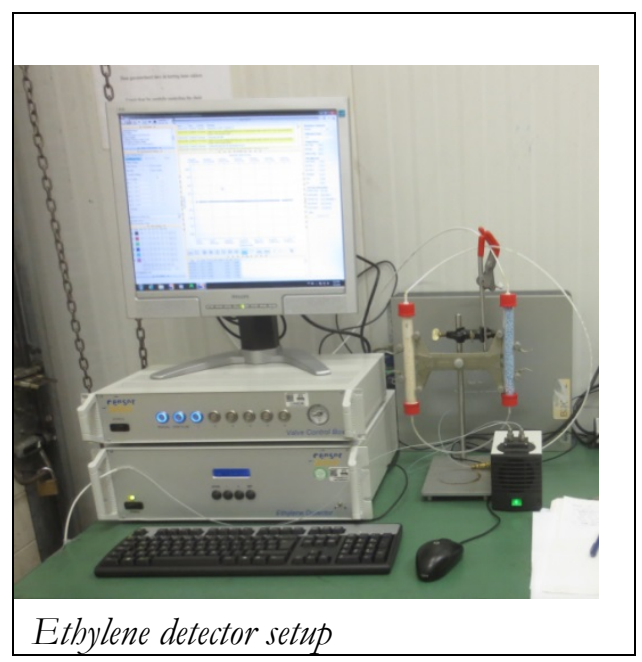
pump (approx. $3 \mathrm{l} / \mathrm{h}$ ) and ethylene concentration was monitored in time.

\subsection{Air speed measurements}

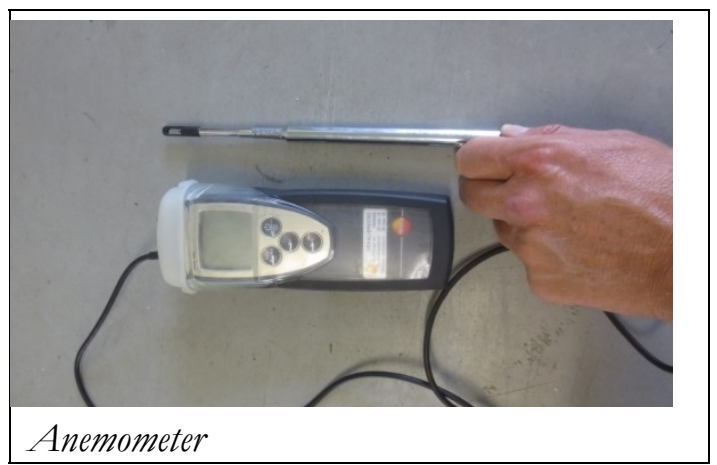

Air flow velocity adjacent to the filters was measured in both situation 3 (filters mounted at return air grid) and 5 (filters mounted at door end) using a Testo 425 hot wire anemometer. 


\section{Results}

Initial testing showed that ethylene decay curves could be considered linear over a time scale of 4 to 8 hours, resulting in $\mathrm{R}^{2}>0.99$. It was decided to use a relatively high ethylene concentration of $750 \mathrm{ppb}$ as start value for calculation of ethylene removal speed. Rate constants were estimated by the tangent of the linear trendlines.

Over 21000 ethylene concentration measurements were used to generate the next graph that shows how fast ethylene disappears from the refer using various settings.

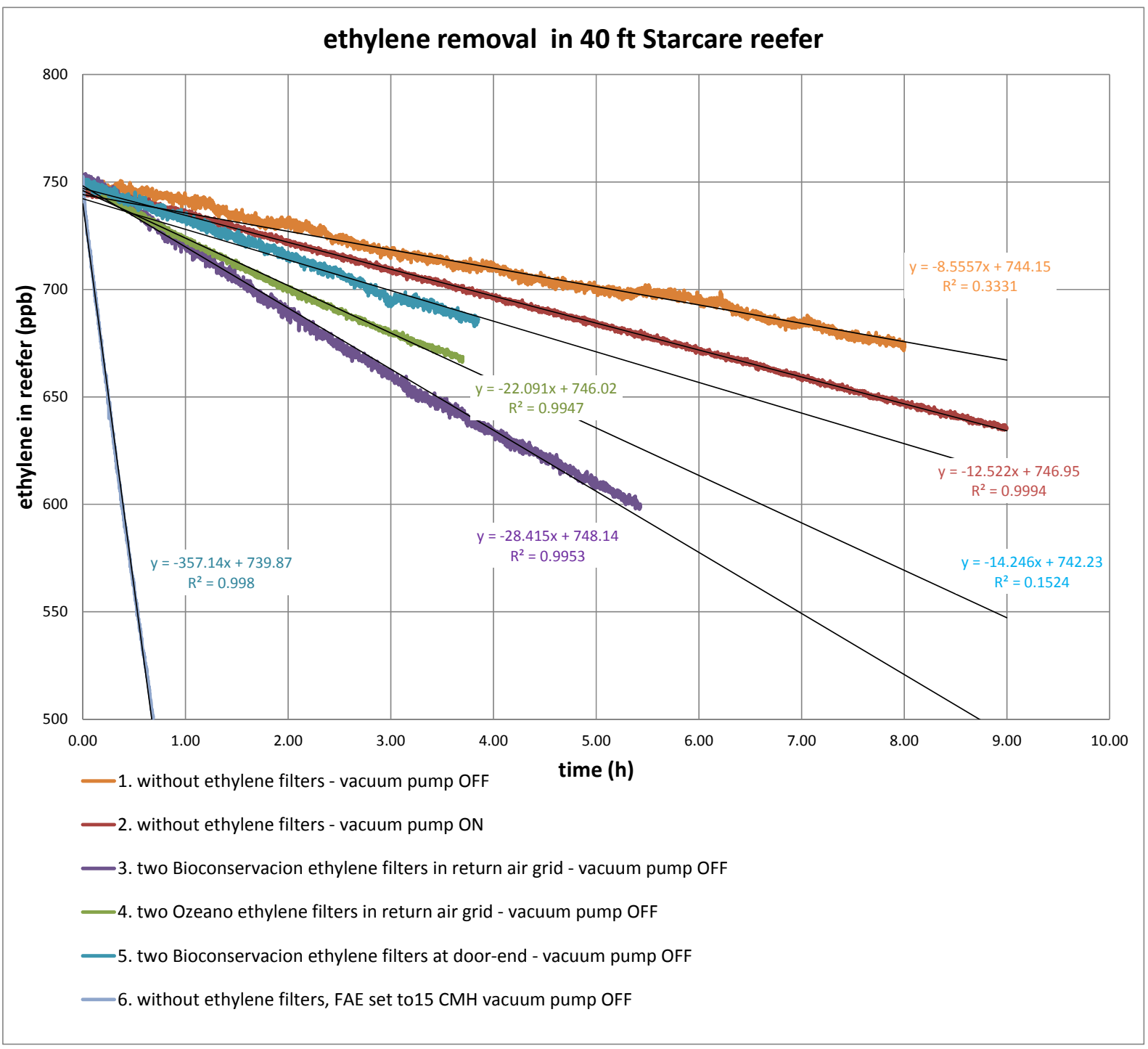

Ethylene reduction in time using various settings/scrubbers 
Object 1. without ethylene filters - vacuum pump OFF is indicative of the leak rate of the closed reefer with CA curtain installed. This leak rate is subtracted from the other measurements to quantify the effect of the other interventions. Leak rate after first closure of the CA curtain and after repetitive closures was comparable, various measurements did not differ more than $2.5 \%$ in ethylene reduction speed (data not shown). In other words: repetitive closing of the CA curtain did not result in significant changes in leak rate.

It is not unlikely leak rate may vary between individual reefers, which should be taken into account when interpreting results.

From the rate constants derived from the tangents, the actual amount of ethylene that was removed from the reefer in time was calculated. Reduction of $1 \mathrm{ppb}$ ethylene in a $66.125 \mathrm{~m}^{3}$ reefer is equivalent with $0.066 \mathrm{ml}$ ethylene removal.

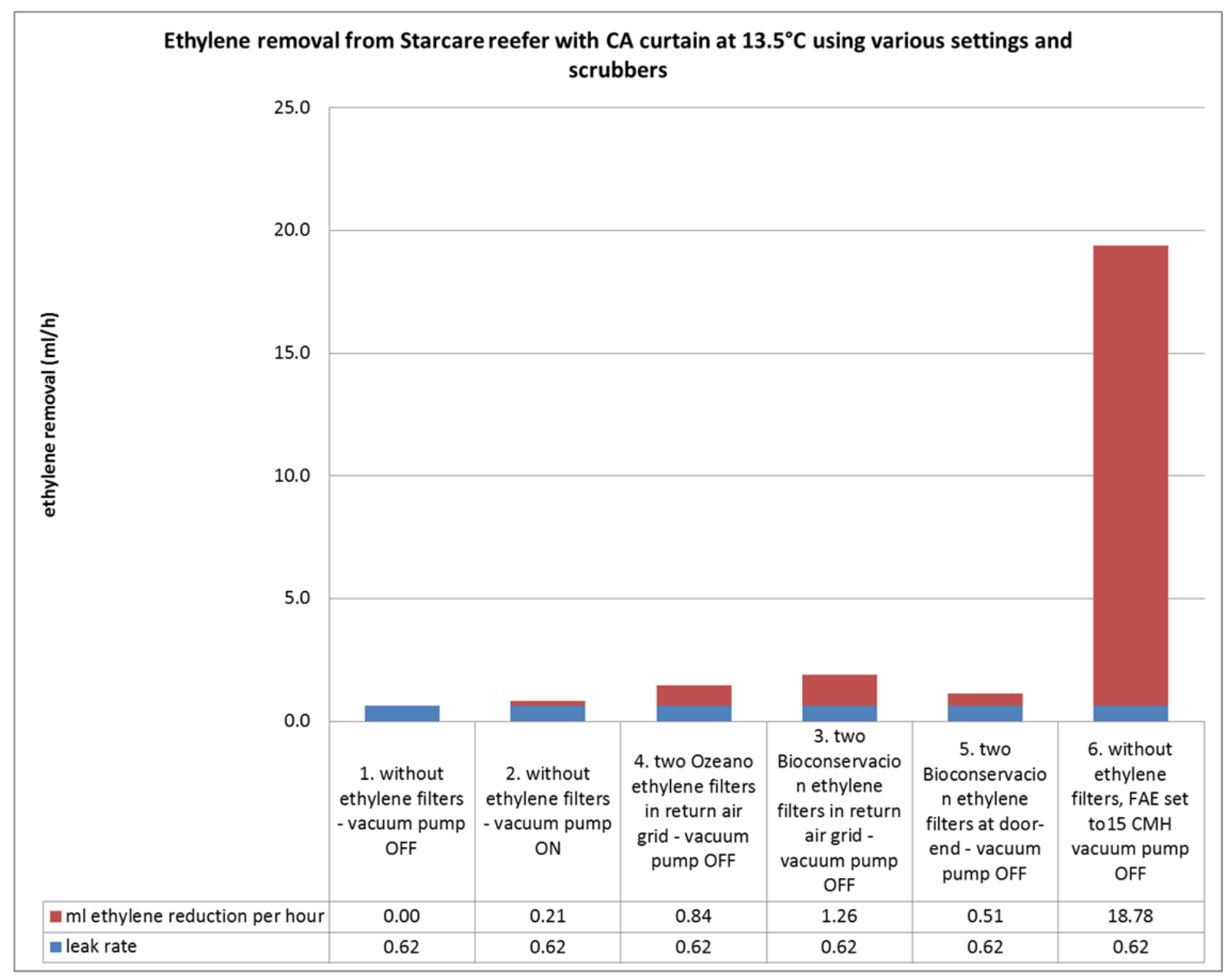


Leak rate (1) accounted for a reduction of ethylene of $0.62 \mathrm{ml} / \mathrm{h}$ in this reefer.

Vacuum pump operation for CA control (2) accounted for an extra $0.21 \mathrm{ml} / \mathrm{h}$ reduction.

Two Ozeano (4) or Bioconservacion (3) filters at the return air grid reduced ethylene with respectively 0.84 and $1.26 \mathrm{ml} / \mathrm{h}$. In other words, capacity to remove ethylene is $33 \%$ lower for the Ozeano filters compared to Bioconservacion in this situation.

Air speed measurements near the filters when placed on return air grid or near the door end showed average airspeeds of $3.9 \mathrm{~m} / \mathrm{s}$ near the return air grid and $0.3 \mathrm{~m} / \mathrm{s}$ near the door end. This difference in airspeed near the filters seems the main factor explaining differences in ethylene reduction. For the Bioconservacion filters the ethylene reduction was $60 \%$ lower when placed at the door end $(1.26 \mathrm{ml} / \mathrm{h}$ ethylene reduction) compared to at the return air grid $(0.51 \mathrm{ml} / \mathrm{h})$. Regular setting of Fresh Air Exchange (FAE) for bananas of $15 \mathrm{CMH}$ (test 6 ) resulted in $18.8 \mathrm{ml}$ ethylene reduction. 


\section{Discussion}

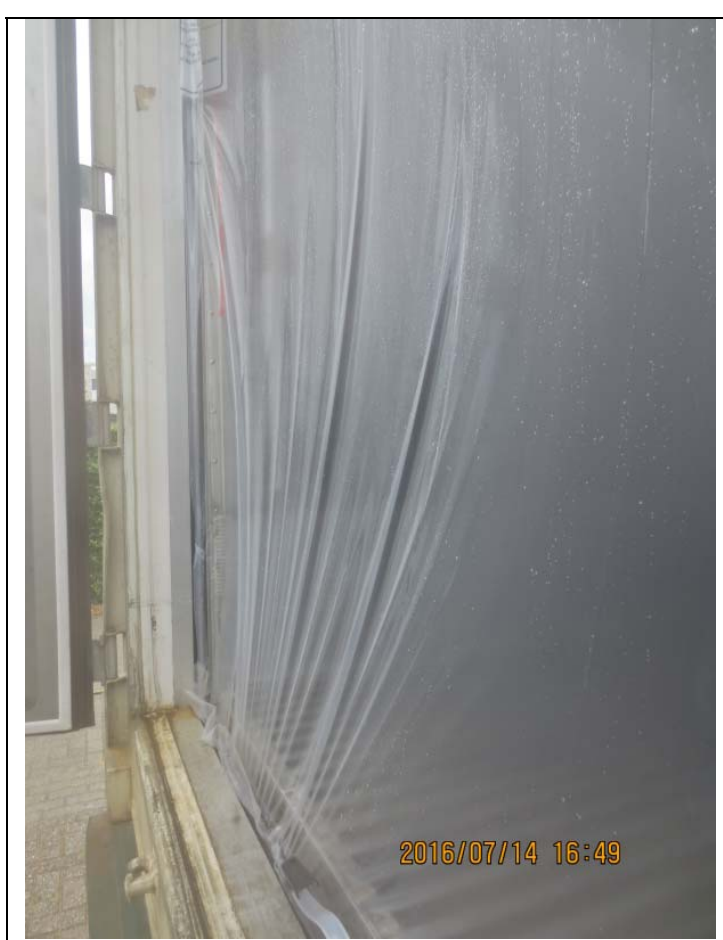

The CA curtain often showed to be bulged inwards when doors were opened. This despite the fact the reefer was precooled and FAE was opened after (re)installation of the CA curtain for some time to prevent this. It did not result in leakage problems during the tests. 


\section{Conclusions}

- Leak rate was $0.62 \mathrm{ml} / \mathrm{h}$ ethylene in this reefer in this test.

- Vacuum pump operation for CA control (test 2) accounted for ethylene reduction of 0.21 $\mathrm{ml} / \mathrm{h}$.

- Two Ozeano (4) or Bioconservacion (3) filters at the return air grid reduced ethylene with respectively 0.84 and $1.26 \mathrm{ml} / \mathrm{h}$. In other words, capacity to remove ethylene is $33 \%$ lower for the Ozeano filters compared to Bioconservacion in this situation.

- For the Bioconservacion filters the ethylene reduction was $60 \%$ lower when placed at the door end $(0.51 \mathrm{ml} / \mathrm{h}$ ethylene reduction) compared to at the return air grid $(1.26 \mathrm{ml} / \mathrm{h})$.

- Air speed measurements near the filters when placed on return air grid or near the door end showed average airspeeds of $3.9 \mathrm{~m} / \mathrm{s}$ near the return air grid and $0.3 \mathrm{~m} / \mathrm{s}$ near the door end.

- Regular setting of Fresh Air Exchange (FAE) for bananas of $15 \mathrm{CMH}$ resulted in $18.8 \mathrm{ml}$ ethylene reduction per hour.

Table below gives an overview of the effects of test conditions on ethylene reduction:

\begin{tabular}{|l|r|r|}
\hline & $\begin{array}{l}\text { ethylene } \\
\text { reduction } \\
\text { (ml/h) }\end{array}$ & $\begin{array}{l}\text { ethylene reduction } \\
\text { (ml/h) additional } \\
\text { to leak rate }\end{array}$ \\
\hline 1. vacuum pump OFF and without ethylene filters. (=leak rate) & 0.62 & 0.21 \\
\hline 2. vacuum pump ON and without ethylene filters. & 03 & 1.26 \\
\hline $\begin{array}{l}\text { 3. vacuum pump OFF and two Bioconservacion ethylene filters in return } \\
\text { air grid. }\end{array}$ & 1.46 & \\
\hline $\begin{array}{l}\text { 4. vacuum pump OFF and two Ozceano ethylene filters in return air grid. } \\
\text { 5. vacuum pump OFF and two Bioconservacion ethylene filters at door- } \\
\text { end. }\end{array}$ & 1.13 & \\
\hline $\begin{array}{l}\text { 6. vacuum pump OFF and without ethylene filters, FAE (Fresh Air } \\
\text { Exchange) set to15 CMH }\end{array}$ & 19.42 & 0.84 \\
\hline
\end{tabular}

The airspeed near the filters seems a major factor in ethylene reduction. For the Bioconservacion filters the ethylene reduction was $60 \%$ lower when placed at the door end compared to at the return air grid. 


\section{References}

Cristescu, S. M., et al. (2008). "Laser-based systems for trace gas detection in life sciences." 92(3): 343-349.

Vries, H. S. M. d. (1996). "Non intrusive fruit and plant analysis by laser photothermal measurements by ethylene emission." Modern Methods of Plant Analysis $\mathbf{1 8}$. 